\title{
New columns for architecture in reinforced concrete
}

\author{
Nuevas columnas de hormigón armado para la arquitectura
}

David Jolly Monge (Main and Corresponding Author)

Escuela de Arquitectura y Diseno

Pontificia Universidad Católica de Valparaiso

Matta 12, Recreo Viña del Mar (Chile)

david.jolly@ead.cl

Manuscript Code: 822

Date of Acceptance/Reception: 04.12.2017/28.10.2016

DOI: 10.7764/RDLC.16.3.489

\begin{abstract}
This paper concerns the provision of new architectural forms in reinforced concrete, obtaining volumes with a double curve surfaces at a reasonable cost, constructed using flexible formwork. Through design research (research by design) 8 types of columns made of in situ reinforced concrete are achieved. An architectonic element with optimal spatial quality and an organic form, with a surface not requiring another finish is the end in mind. The construction process is relatively simple given the results obtained and the construction of prototypes during building work on site opens up the possibility of using this technology on building sites everywhere reinforced concrete is available.
\end{abstract}

Key words: Reinforced concrete, columns, flexible formwork, research by design, organic form.

Resumen

Este artículo trata de la construcción de nuevas formas en hormigón armado para la arquitectura, al obtener volúmenes con superficies de doble curvatura a un costo razonable, construidos con moldajes flexibles. Se han obtenido por medio de la investigación por diseño 8 tipos de columnas de hormigón armado realizadas in situ, en la obra. Es un elemento arquitectónico de gran calidad espacial con una forma orgánica, cuya superficie de óptima terminación no requiere otro acabado. El proceso constructivo es relativamente simple para el resultado obtenido y su construcción en el sitio de la obra abre la posibilidad de erigirlo en cualquier parte donde se pueda emplear el hormigón armado.

Palabras clave: hormigón armado, columnas, moldajes flexibles, investigación por diseño, forma orgánica.

Introduction

Reinforced concrete is a key building material of modern architecture and the habitable infrastructure of today's world. This is due to the extraordinary virtues met in this material: mechanical resistance with incombustibility and resistance to high temperatures.

This artificial material, taking this adjective in its direct sense, uniting the terms art and craft, is basically made up of two components: a steel structure which is covered by cement in a semi-liquid state which after a physical-chemical process passes from an amorphous moldable state to a solid which acquires the resistance to compression that characterizes it, the steel inside responsible for resisting tension, forming an element that resists both forces in a calculable and predictable way.

Now the virtues of this material are limited by its condition of moldability, that must be maintained for the duration of curing by a container which gives it a form.

And the form is the issue to which architects devote themselves: the form of the limits which construct the spaces we inhabit. That is why this research into the form that reinforced concrete can acquire has been addressed by architects.

Now we can confirm that the greatest number of forms given to elements or parts built with concrete have something in common: they are formed by rectilinear planes. The volumetric elements constructed with concrete thus have a prismatic form, said generally to be through the intersection of rectilinear planes (West, 2016); with them, you cannot access to double curve continuous mantles, only an approximation with a prism on many faces but that solution is expensive.

Exceptions exist, amongst whom we note Miguel Fisac (1913-2006) who used flexible formwork to give a plastic surface to the exterior of his works in concrete. In the early twentieth century, some patents involving its use appear, and the real development of this technology in this century, begins with a laboratory dedicated to this purpose CAST (Centre for 
Architectural Structures and Technology), founded by architect Mark West in Canada in 2002 (Veenendaal, West, \& Block, 2011). And a number of researchers that started demonstrating the advantages of this technology, among them its improvement to the hardness of concrete on its surface because it expels the excess water from the mortar, as verified in a research in the University of Bath (Orr, 2012). Also some non prismatic columns may carry twice the load at equal amounts of concrete depending on their form. (Pedreschi, 2015). Flexible formworks are among a 100 to 300 lighter than a traditional formwork, and could be used several times, and may cost ten times less (West, 2005). And that 'fabric form-work is structurally safe alternative for forming reinforced concrete columns' (Delijani, West, \& Svecova, 2015)

The research presented here thanks to Fondecyt (FONDECYT, Fondo Nacional de Desarrollo Científico y Tecnológico), Project № 11140640 developed in Corporación Cultural Amereida, Quintero, Chile, "Concrete Architectonic form done with flexible formworks", takes another step towards opening up a new field of organic forms for architecture made with reinforced concrete elements. It seeks to open two possibilities simultaneously: firstly proportioning new forms of architecture and secondly, realizing these forms at the location where the building is taking place, i.e. in situ. This is because until now research in this field has realized such construction elements either in the laboratory or the factory space of the prefabrication industry. Now we have taken this research to the building site, extending the possibility of this kind of manufacture to all places where works of architecture are being built.

This whole argument is rooted in a simple but radical fact: the formwork for reinforced concrete has changed from being made exclusively of rigid materials to incorporating flexible material such as fabrics and membranes. The cement of the concrete is contained by a thin sheet of fabric where a negotiation is produced between the semi-liquid mass and the fabric that resists tension, fabric, and cement arriving at an equilibrium shape through gravity, which makes its volume fill a peculiar form. This peculiarity that belongs to a state of wet weight makes us name it an 'organic form', as once rigid, its form with double curvatures sometimes recalls the organic nature of living bodies.

Methodology

This research is conducted by postulating a methodological thesis, which holds that a scale model has a similar behavior to that of a full-scale 1:1 prototype, in terms of the form (Jolly, Eyquem, \& Jolly, 2011). That is to say, the form obtained in a scale model and with a much finer-grained material, gypsum plaster, modeling the concrete, is likely to be able to work at full-scale; and very importantly, what will not work at reduced scale will not work at full scale.

This working thesis confirms the previous findings of Veenendaal \& Block (2012), who argue that physical models cannot be replaced by digital models in the use of flexible formwork to determine what it is possible to design, and more importantly, that the physical model discloses how you can finally build the element in question. This basic argument opens the possibility of research in the workshop, which is now known as design research (research by design). So the knowledge gained up to date is based on the experience of laboratories and workshops.

Experimentation with flexible formworks has led the development of new forms. And the word new means at least two dimensions, the first is a new figure, their profile, the continuity of double curved surfaces in three-dimensional bodies. The second dimension is that these bodies are obtained through a relative simple constructive operations.

The methodology consists of an experiment task done in a construction workshop. This is divided into two basic steps, first building scale models done on the workshop. The second step is the prototype testing which is done in full scale 1:1 in a work of architecture (Models are done in plaster scaled 1:10. Prototypes are done on reinforced concrete scale $1: 1)$.

The methodology of work with architectural models operates with a procedure which can distinguish at least three steps, the first is to imagine a possible form, whether is a mental proposition or may be recognized in an existing body, then this figure is translated to a drawing or other mode of representation, allowing a formal purpose, who leads to the next step that is some realization.

This research sought to achieve new forms of architecture in concrete with flexible formwork. The design strategy was to find new forms for a primary architectural element: the vertical column.

There is also another research way opening by this days, as the forms obtained with flexible formworks are not possible to predict with digital models, research knowledge may be improved by the techniques of massive data capture (Lluis $\mathrm{i}$ Ginovart, Costa-Jover, Coll-Plà, \& Puche-Fontanilles, 2016). Measuring the differences on what is projected and what is obtained in the models and prototypes. This accurate technology may also help the structural analysis of this new forms. 


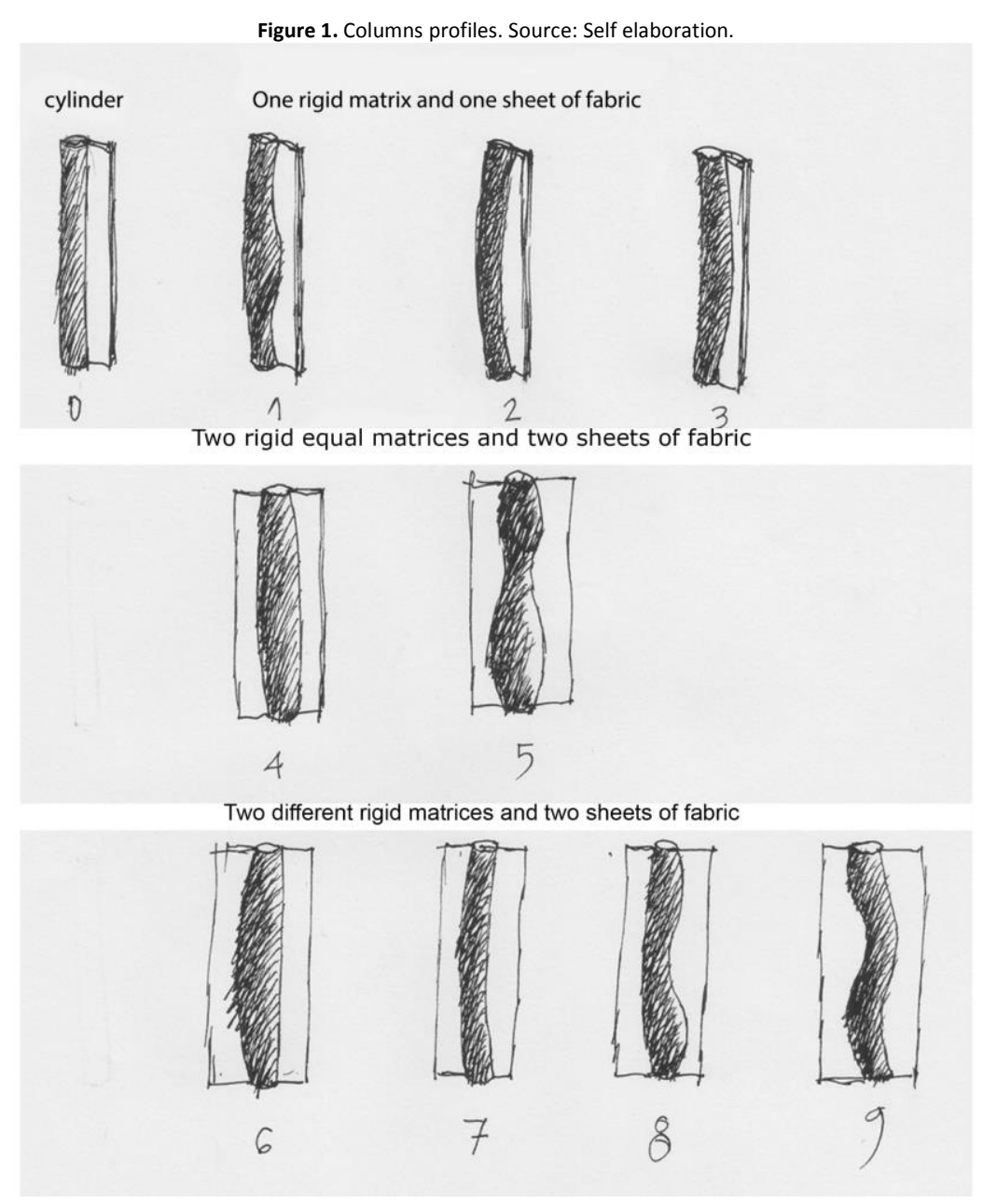

Eight shapes for a column obtained out of the basic figure of a cylinder. The difference among them is obtained from the number of a rigid matrices: one or two; the number of fabric sheets, and the profile of the rigid matrix.

At this point, it is important to discuss the aim concerning location that this research project envisaged from the outset. Early studies and research with flexible formwork for concrete have been done basically in two arena: workshops or laboratories and the precast-concrete fabrication industry. Both represent a working environment protected from the spatial conditions presented by a building site. For this reason, this project started by proposing that the full-scale 1:1 prototypes would be realized on the site of a project so that what is made is subject to the requirements of a typical building process and in turn could be replicated anywhere a project is erected not just in a laboratory or factory.

Therefore, in accordance with the thesis proposed, the research has experimented with models at 1:10 scale with columns of a section equal to $1 / 10$ of their height, i.e. plaster models of a section of the order of $3 \mathrm{~cm}$ in diameter and $30 \mathrm{~cm}$ high. Alternatives to the vertical profile of columns with a cylindrical section of equal diameter at the base and the head have been done.

About 112 models were made, which can basically be classified into two large families that concern their mode of construction: with one vertical rigid matrix and with two such matrices (Figure 1).

The methodology of the workshop process is to give shape to the flexible formwork by fixing the fabric to wooden brackets that permit it to receive the gypsum plaster (Figure 2). The plaster has a slightly different behavior to concrete. Since it behaves as a liquid this involves having a sealed formwork unnecessary with the concrete. To achieve a model several attempts are made to learn the outcome of each experiment, at this stage regularity is sought, leaving out what is achieved by chance. Thus those examples that achieve a regular continuity of surface, without presenting accidents, folds or wrinkles constitute the models. When it comes to building the columns, control of sections was pursued so that later they could be considered suitable for structural calculation. This is a design restriction which in turn unlocks the variants achieved, all columns have a circular section perpendicular to their length; so all are variants that arise from the basic shape of the cylinder which is the basic matrix of the column. 
Amongst the models obtained 11 distinct types could be distinguished according to their profile and the number of matrices and cloth sheets required for their fabrication. Of these, the 8 types considered most apt for a column acting as an architectural element was chosen.

Figure 2. Column models. Source: self elaboration.

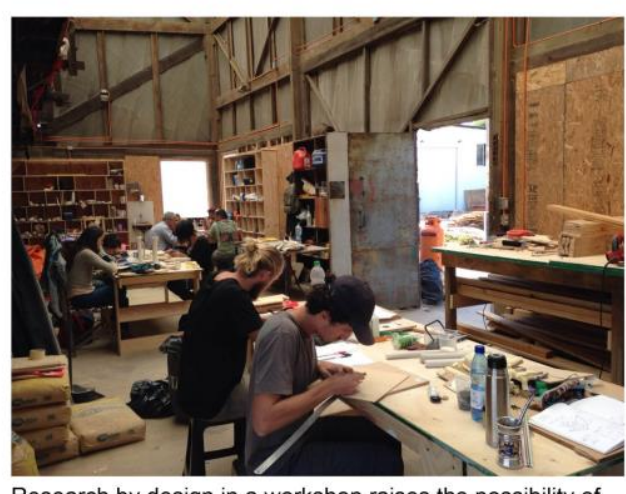

Research by design in a workshop raises the possibility of new forms for concrete.

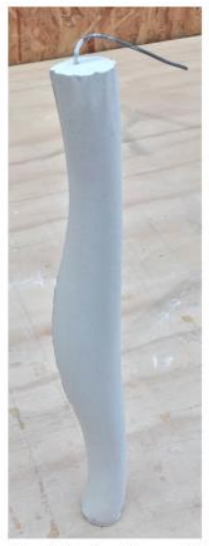

Model of column 01 in plaster 1:10.

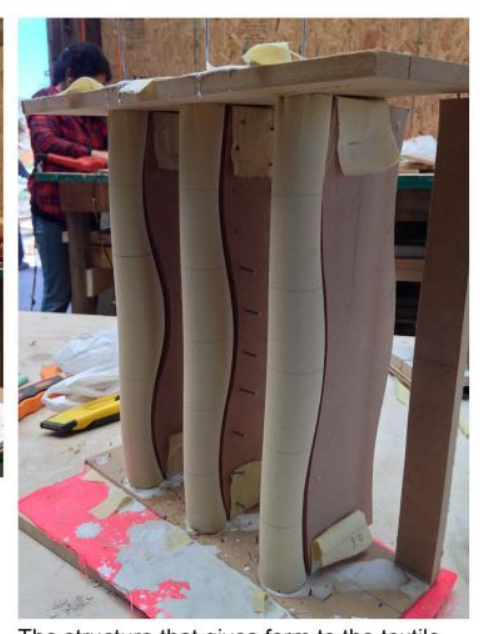

The structure that gives form to the textile filled with plaster.

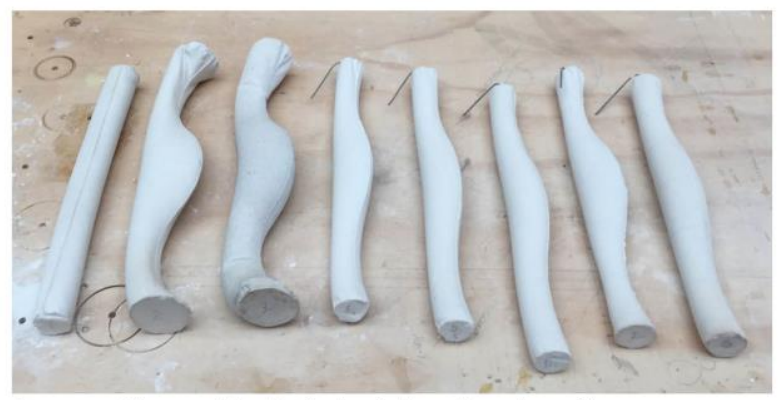

Seven models searching for the best shape for column 01 .

Modeling the figures for the columns in a workshop research is a methodological thesis that may obtain the shape of each one and the way it could be built.

In moving from the model to the prototype not only the dimensions but also the material was changed; thus in the model a thin fabric of an ordinary type typical in garment construction was used whereas in the prototype at scale 1:1 a geotextile fabric, type T2100, used typically in the construction of roads and dams, was employed. It is a fabric that behaves as such, with great tensile strength. Whereas $3 \mathrm{~mm}$ and $10 \mathrm{~mm}$ plywood plates are used in the models, plates of $20 \mathrm{~mm}$ plywood and slats of various square sections are used in the final formwork. In this way what is achieved in the model, shapes of a minimal weight that anticipate a similar behavior in the geotextile fabric combined with the cement, must necessarily translate to the gravitational conditions where the reinforced concrete involves a weight of at least 2.5 tons per cubic meter with the consequent pressure on the fabric. This involves the construction of supports for the fabric adequate to sustain the weight of the concrete and ensure its setting in the shape desired.

The drawing shows the parts needed to build a column $337 \mathrm{~cm}$ high. On upper part the rigid elements that sustain the fabric. On the lower part the textile with its drawing and measures (Figure 3 ).

Once the 8 types of columns had been selected from the models obtained, 17 columns were erected, constituting the threshold of the work entitled Pórtico de Los Huéspedes, de la Ciudad Abierta.(de Arce, Oyarzun, \& Rispa, 2003).

Here the unusual status of the Open City should be noted that enables and indeed makes possible the execution of an experimental project where research can be part of building works that are later to be inhabited.

Seventeen columns arriving all to the same horizontal level. Different shapes, size, and proportions did on site, they prove to be done in any place where a building is done. 
Figure 3. One column fabric formwork drawings Source: self elaboration.

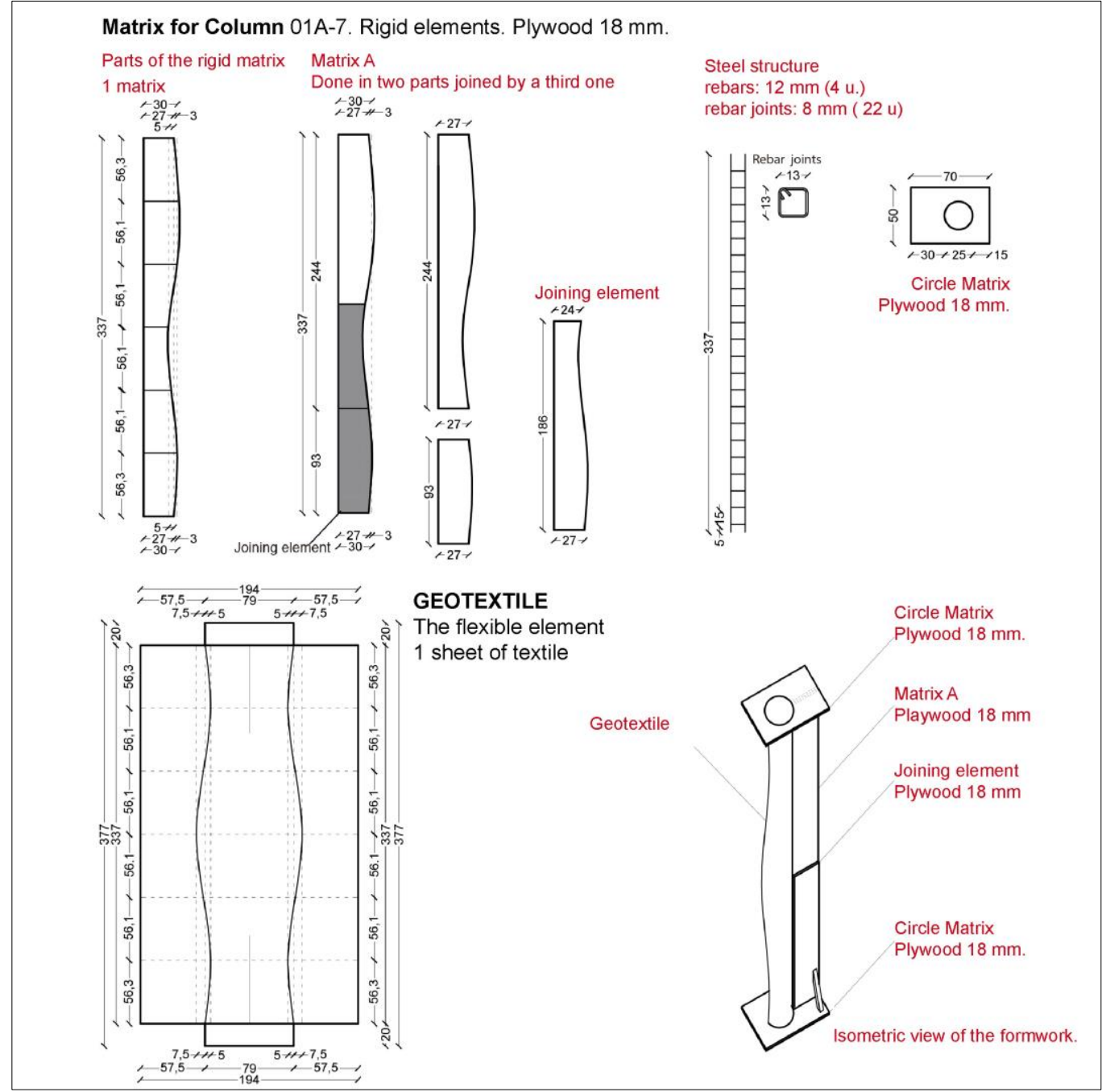

Results

The first result obtained is methodological, the thesis posed concerning the relation between model and prototype is a fruitful method of exploration that oscillates between what the architect imagines and what it is possible to build. This is a genuine path that links what the hand and mind can draw like an arabesque and what can be erected taking into account the weight and behavior of the material. Then a spatial-design-led decision is necessary concerning the shape that can contribute most effectively to the architectural form.

Thus research into the form that reinforced concrete can take opens the possibility of building architectural elements with a traditional shape like a column with entasis, which could only previously be constructed by stone carving; alongside a range of new forms not deemed possible for architecture previously.

Because it determined the selection of column shapes deemed worth building as full-scale prototypes in this case, how the approach 'form that is reticent' was matched to column choice is worth outlining briefly. With all the care and dedication its realization involves, a work of architecture is intended to accommodate human habitation, i.e. inside it life needs to be able to be lived to the full. For this to happen the limits constituted by the architecture are 'removed', they are 'not present' all the time, they do not 'weigh' on inhabitants in order that an interior can be given over to events. In seeking an architectural form that 'withdraws', what is sought through the rhyme of word and action is a situation where the accommodation of action is embodied in the spatial virtue of what is built.

Pursuing this intention, the search for form in the models was directed to identify the shape that achieves the most spatiality with the least variation. For example, a variation in arc-height of $1 \mathrm{~cm}$ in the curvature of a column of three meters high is not enough to be perceived, and one of $40 \mathrm{~cm}$, being an isolated built figure, does not allow itself to be 
used as a column; but an arc-height $5 \mathrm{~cm}$ out of the usual true vertical leaves the column with a new 'will to form'. So of the 8 most suitable families selected the example that best met this condition of retirement was chosen.

Figure 4. Column Sections and the topography. Source: self-elaboration.
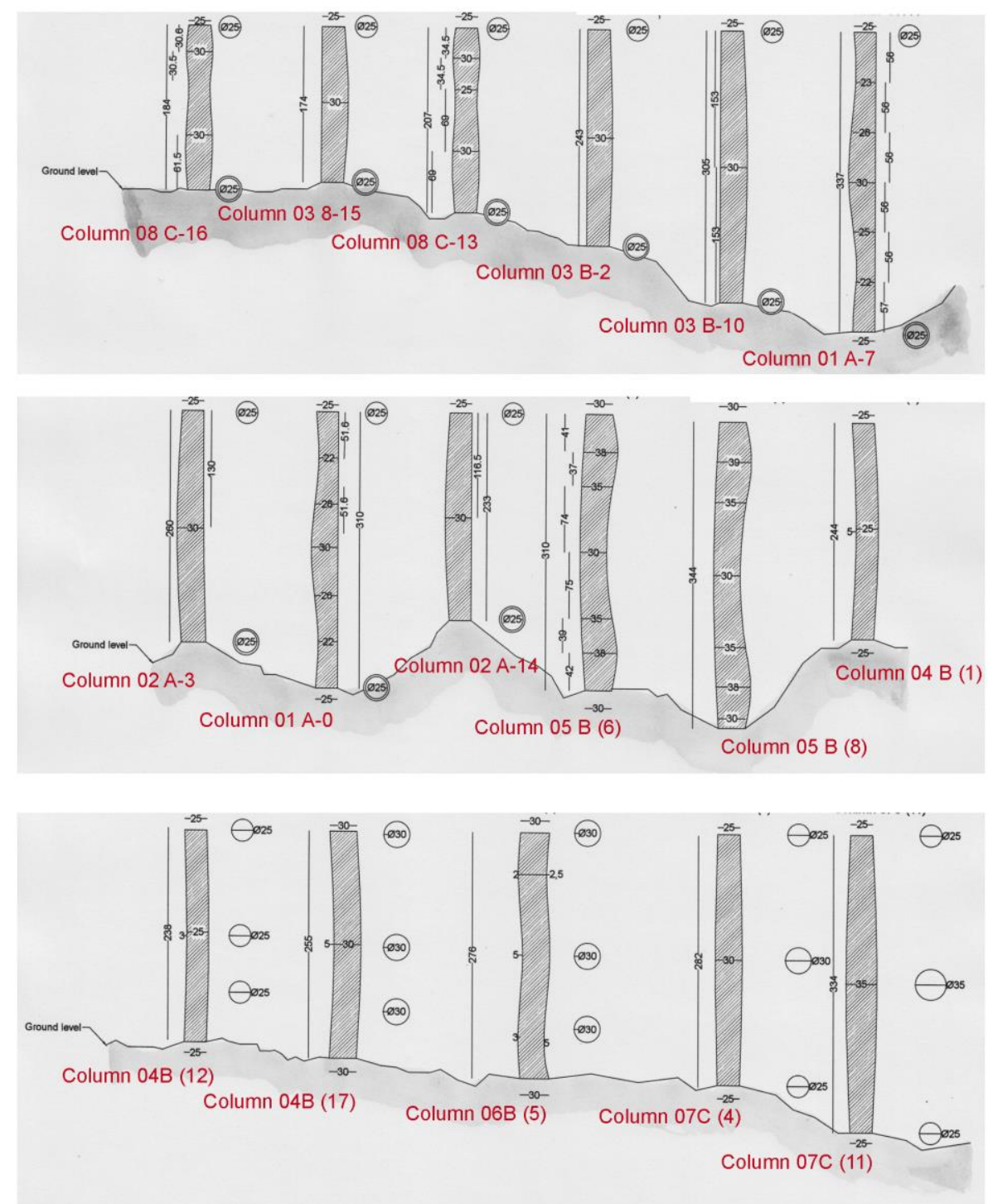

Then, the second result is the realization of a reasonable number of architectural elements, 17 columns made in situ in the work Pórtico de Los Huéspedes de la Ciudad Abierta (Figure 4). They demonstrate that it is possible to construct architectonic elements in reinforced concrete with extremely simple formwork since in each formwork cloth sheets were used requiring no cuts or seams, the shape given only by trapping the fabrics between the rigid matrices. Finally, the construction on site guarantees the possibility of replicating the process described anywhere a work of architecture can be erected with reinforced concrete (Figure 5).

Building the column starts drawing the geotextile, then fixing it to the rigid parts, the formwork is attached to the foundation and then the concrete is poured inside. The whole building process took place in a normal build place with the students, no qualified workers where required.

Reinforced concrete up to date had only the possibility to be done in prismatic figures done with rectilinear surfaces. The flexible formwork permits double curvature surfaces giving place to a new organic form for this architectonic element (Figure 6). 
Figure 5. The building process of the columns. Source: self-elaboration.
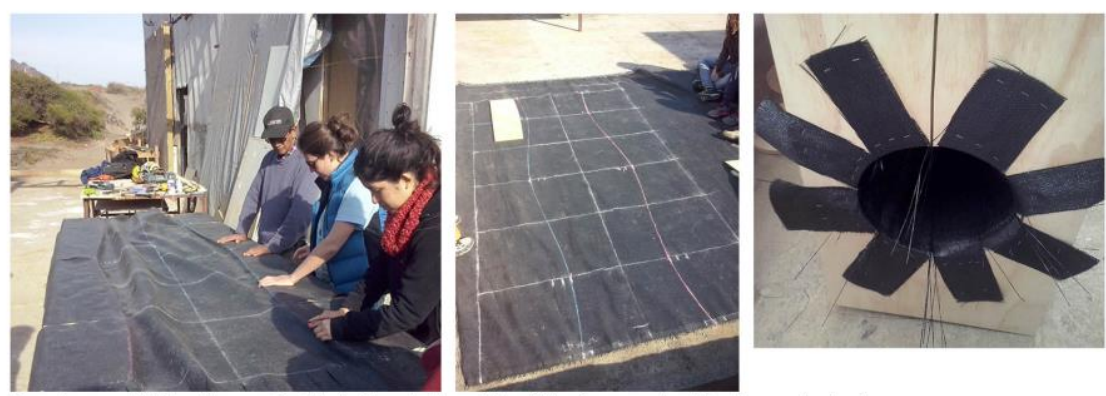

Drawing and fixing the geotextile to the rigid matrix of the formwork with glue and staples.
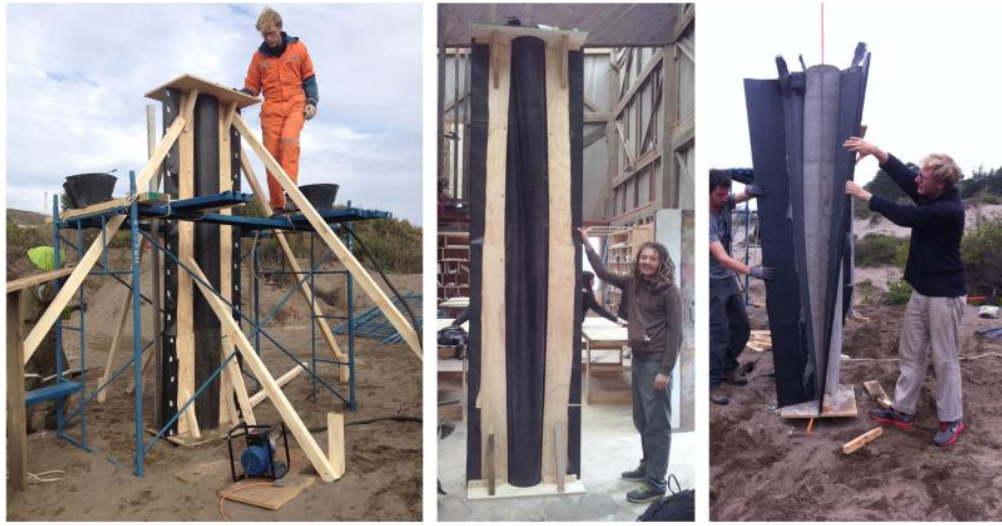

The formworks stands as an independent body that is fixed to the ground before concrete pouring takes place. Later, once the concrete has hardened, the geotextile and ply formwork is taken apart.

Figure 6. Columns in their site. Source: self elaboration.

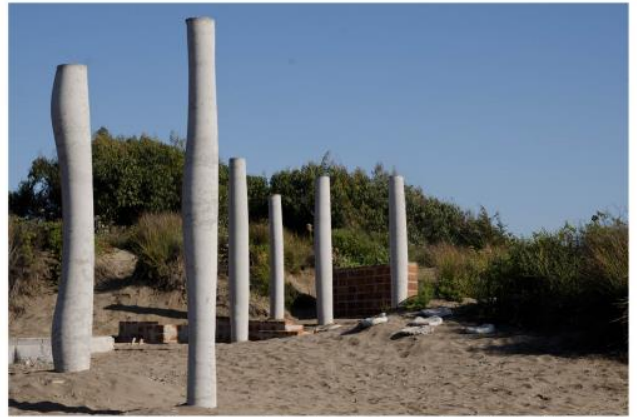

Columns are a basic architectural element: with flexible formwork it is possible to achieve new forms for them.

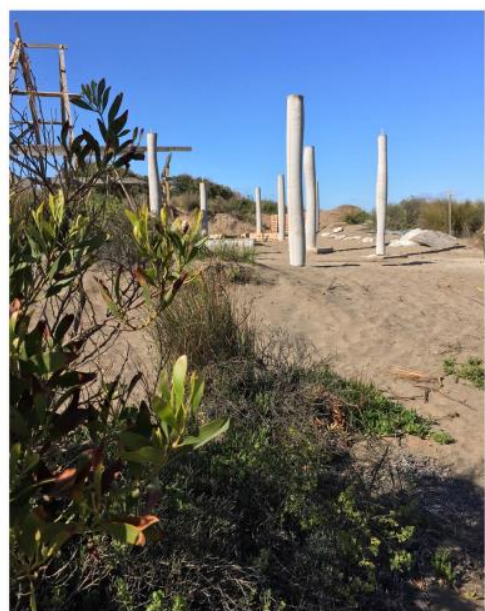

Arguably, the organic form obtained with flexible formwork is in closer harmony with natural form.

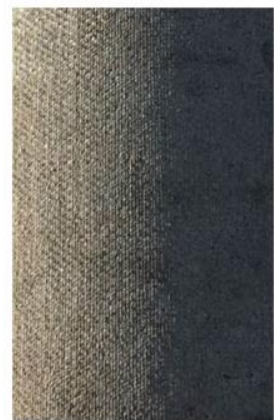

As a bonus, the textile formwork gives each column a finished surface.

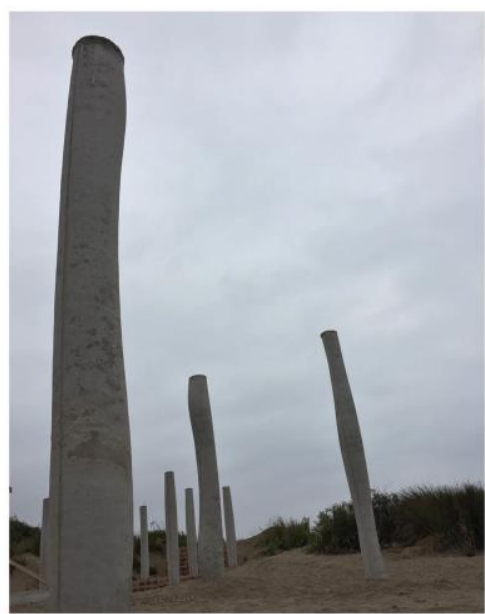

The seventeen built columns in situ 
Once this research is done, it proved that the methodological hypothesis developing models is a possible way to find new forms of concrete.

It is possible to obtain new regular forms for concrete reinforced columns with flexible formworks.

This new forms may be done anywhere reinforced concrete is available.

This research raises the possibility to develop the form of columns for tall buildings basement.

After the form obtained with plaster models, there is a field to be developed in computer models. There is a research to be done in order to know the fabric limits to be deformed in a regular way.

References

de Arce, R. P., Oyarzun, F. P., \& Rispa, R. (2003). Escuela de Valparaíso: ciudad abierta. Tanais. Retrieved from https://books.google.cl/books?id=91aGPgAACAAJ

Delijani, F., West, M., \& Svecova, D. (2015). The evaluation of change in concrete strength due to fabric formwork. Journal of Green Building, 10(2), 113-133. https://doi.org/10.3992/jgb.10.2.113

Jolly, D., Eyquem, M., \& Jolly, V. (2011). Encofrados flexibles. Otra forma para el hormigón. Arq, 78, 58-64.

Lluis i Ginovart, J., Costa-Jover, A., Coll-Plà, S., \& Puche-Fontanilles, J. M. (2016). Técnicas de captura masiva de datos: Estudio comparativo para el análisis de espacios complejos en patrimonio arquitectónico. Revista de La Construcción, 15(1), 42-50.

Orr, J. (2012). Flexible formwork for concrete structures. University of Bath. UK.

Pedreschi, R. (2015). A preliminary study of the strength of non-prismatic columns using fabric formwork. In Proceedings of the International Society Of Flexible Formwork (ISOFF) Symposium 2015, Amsterdam. Koninklijk Instituut Van Ingenieurs.

Veenendaal, D., West, M., \& Block, P. (2011). History and overview of fabric formwork: using fabrics for concrete casting. Structural Concrete, 12(3), 164-177. https://doi.org/10.1002/suco.201100014

Veenendal, D. \& Block, P. (2012). Computational form finding for fabric formworks: an overview and discussion. In J. et al. Ohr (ed.). Proceedings of the 2 nd international conference on flexible formwork. University of Bath, UK.

West, M. (2005). A brief description of fabric formed concrete. [online]. Retrieved from http://www.umanitoba.ca/faculties/architecture/cast/CASTonline. html

West, M. (2016). The fabric formwork book: Methods for building new architectural and structural forms in concrete. [online]. Taylor \& Francis. Retrieved from https://books.google.cl/books?id=1At6DQAAQBAJ 